\title{
A simbologia da transição nas cenas de personagens da realeza calçados no Egito da segunda metade do Reinado Novo
}

\author{
Cássio de Araújo Duarte*
}

\begin{abstract}
DE ARAÚJO DUARTE, C. A simbologia da transição nas cenas de personagens da realeza calçados no Egito da segunda metade do Reinado Novo. Revista do Museu de Arqueologia e Etnologia, São Paulo, 17: 293-304, 2007.
\end{abstract}

Resumo: Representações de indivíduos calçados ganham espaço durante o Reinado Novo, quando pela primeira vez, personagens da realeza são ilustrados dessa forma. Somados ao significado e função básicos da proteção do solo e suas impurezas, as sandálias também podem conter ilustrações dos inimigos clássicos do Egito com a finalidade de estes serem submetidos, por meio de um ato de magia simpática, ao controle do rei egípcio. Todavia, em uma série de pinturas desse período que ilustram os monarcas calçados em seus túmulos, podemos encontrar a alusão a um outro significado que, quando cruzado com outras fontes, apontam para iminência da transição para a outra vida. Com o objetivo de destacarmos este aspecto, voltaremos nossos olhos para as representações do túmulo da rainha Nefertari, 19a dinastia, e de alguns outros exemplos em túmulos do Vale dos Reis.

Palavras-chave: Egito antigo - Arte egípcia - Simbologia das sandálias Arte funerária.

A inda que presentes em uma série de registros de túmulos datados do Reinado Antigo e Médio, figuradas nos pés do proprietário, as sandálias só se tornarão freqüentes nesse tipo de circunstância a partir do Reinado Novo, quando aparecem também os primeiros registros da realeza com esse calçado. Normalmente associadas ao status, à submissão dos inimigos do Egito (VogelsangEastwood 1999: 71, 74-75; Reeves 1995: 155) e ao conceito de isolamento de tudo o

(*) Museu de Arqueologia e Etnologia da Universidade de São Paulo. Doutorando em Arqueologia (menkaura@terra.com.br). que é impuro, encontramos em um repertório iconográfico que reúne registros de túmulos e templos um outro significado que ressalta a afirmação do indivíduo entre os vivos $^{1}$ ou seu período de transição ao pósvida. Para melhor ilustrar o último caso, ressaltaremos seu uso no projeto iconográfico do túmulo da rainha Nefertari, esposa de Ramesses II (c.1279-1213 a.C.).

A sepultura, QV66, descoberta em 1904 pelo arqueólogo italiano Ernesto Schiaparelli, encontrase no Vale das Rainhas (Weeks 2005: 372-387), ao

(1) Aspecto a ser explorado em um outro artigo. 
sul do Vale dos Reis e à margem oeste da atual cidade de Luxor. Tal como os demais túmulos da região, o hipogeu foi escavado em rocha calcária e suas paredes passaram por um tratamento com gesso que permitiu que estas servissem de suporte para os suaves relevos e magníficas pinturas que fizeram do monumento uma das mais importantes referências da arte egípcia da 19a dinastia.

A tumba é constituída por uma escadaria descendente (A) que dá acesso à antecâmara (B), à qual estão ligados, à direita, um vestíbulo $(\mathrm{C}) \mathrm{e}$ uma câmara lateral (D), e, à frente, uma rampa composta com escadaria (E) enviesada descendente que leva à câmara funerária $(\mathrm{F})$ a qual, por sua vez, se vê cercada por duas câmaras laterais (Fa e $\mathrm{Fc}$ ) e outra mais adiante $(\mathrm{Fb})$. Todos os cômodos, com exceção da câmara Fb, são minuciosamente decorados com passagens do Livro dos Mortos, que aludem à jornada da rainha no pós-vida. Aqui nos deteremos especificamente nos registros das duas paredes da antecâmara que ladeiam a escadaria de acesso ao túmulo (Fig. 1).

A primeira ilustração (Leblanc e Siliotti 1993: 123) encontra-se bastante danificada na parte superior direita, onde a rainha está figurada, e na porção inferior esquerda, tomando quase que completamente o trono sobre o qual o deus Osíris está sentado (Fig. 2a). Alguns danos também atingiram os pés de Nefertari e a esteira sobre a qual ela está em pé sem ter apagado o hálux e a extremidade da sandália do pé direito (Fig. 2b). Nefertari está

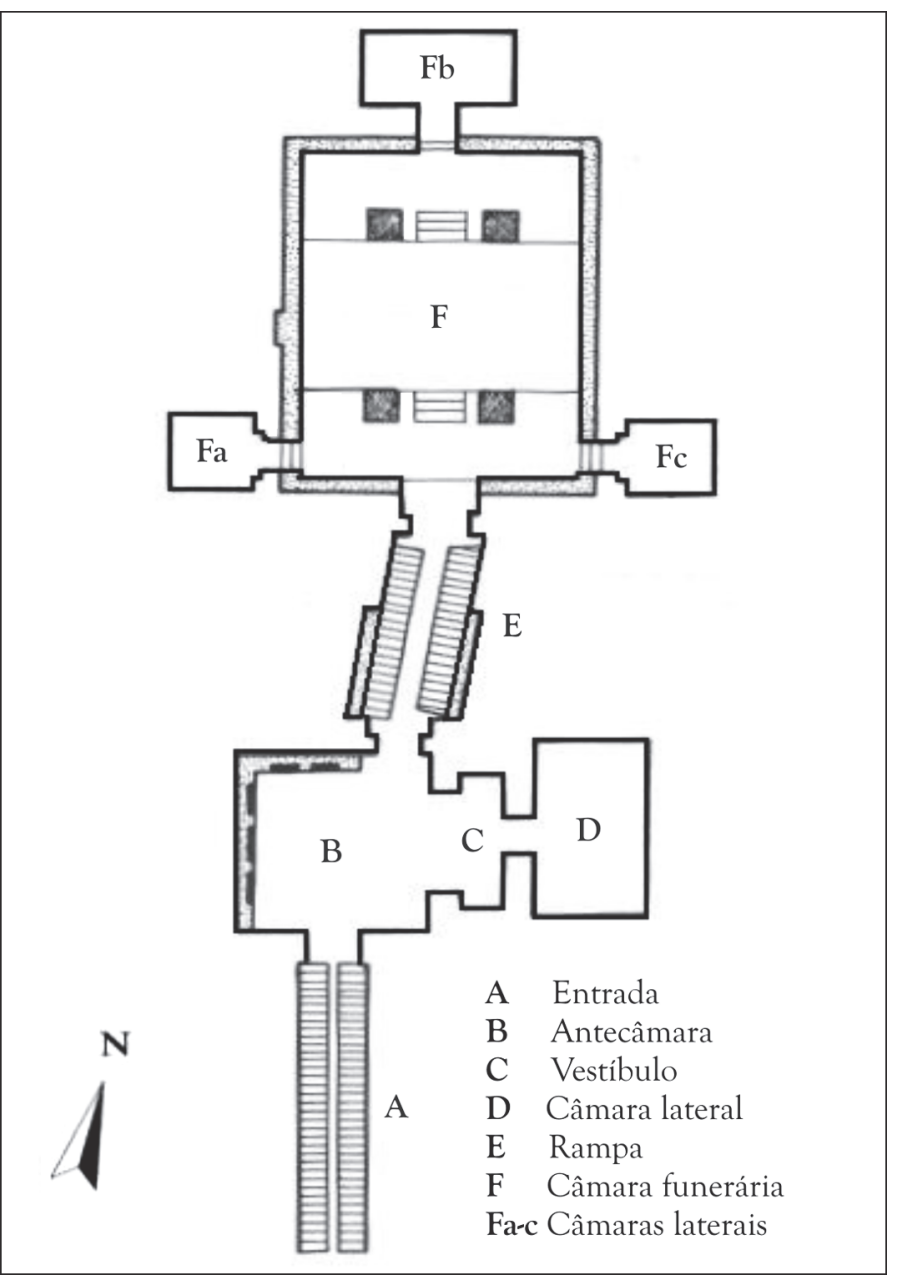

Fig. 1. Planta do túmulo de Nefertari no Vale das Rainhas, QV 66. 
com um longo vestido semi-transparente amarrado na cintura por uma faixa vermelha e, nos braços, que se encontram elevados à altura do peito em atitude de adoração, usa braceletes. Sobre a cabeça, possivelmente portava uma longa peruca - hoje completamente destruída sobre a qual estão um abutre e um modius com duas plumas e um disco solar entre elas. ${ }^{2}$ Diante da rainha e acima, uma inscrição hieroglífica diz: Osiris, a Grande esposa do rei, a Senhora das Duas Terras, Nefertari-Mery-en-Mut, justificada. À frente dela está Osíris, mumiforme, tendo ao peito os dois punhos que seguram os cetros heqa e nekhekh. A cintura é cingida por uma faixa vermelha com duas voltas (tal como em Nefertari) e cujas extremidades estendem-se

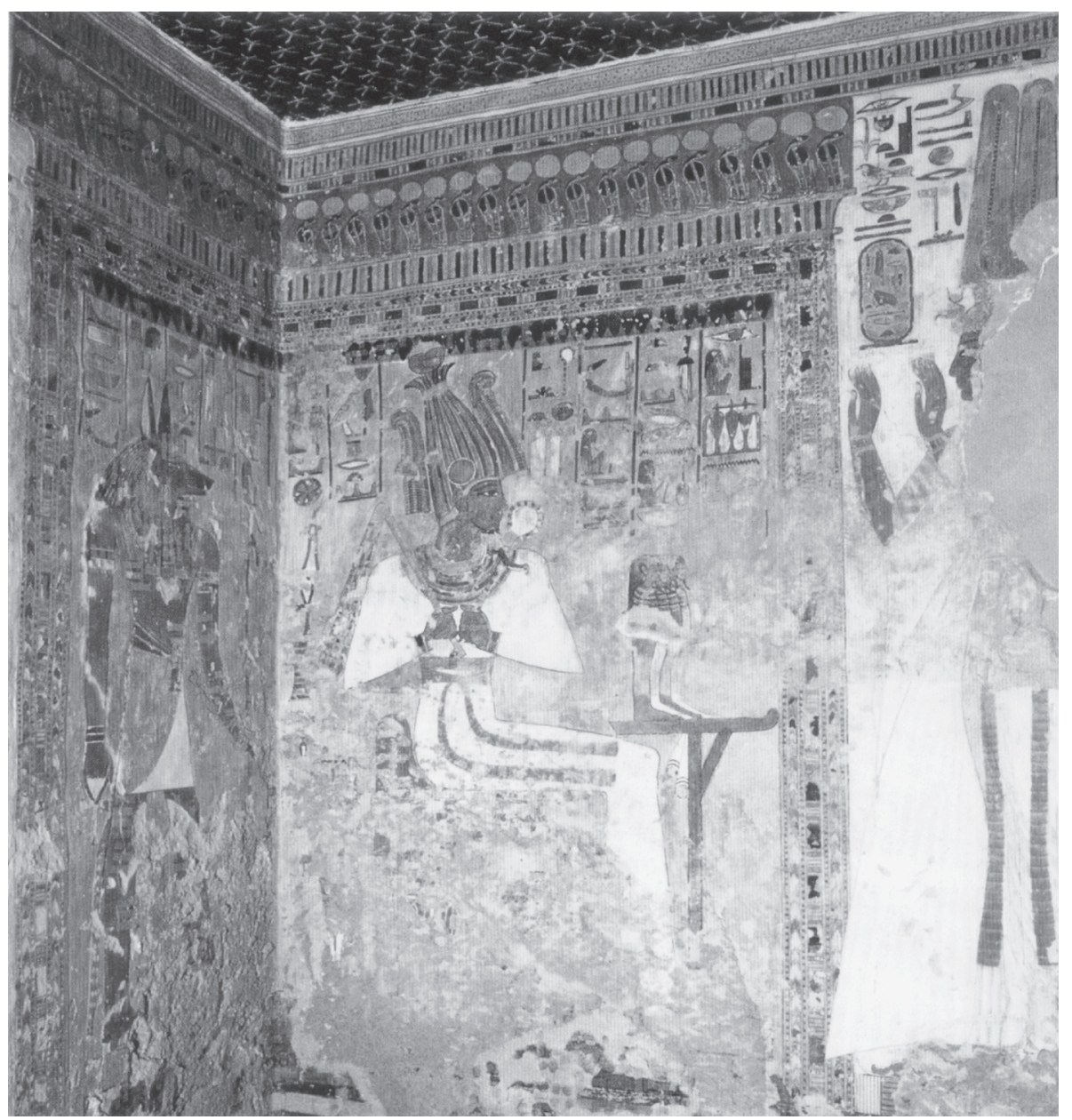

Fig. 2a. Cena de Nefertari adorando Osíris na parede sul do vestíbulo à esquerda do corredor de entrada, 19a dinastia. (Leblanc e Siliotti 1997: 123).

Fig. 2b. Detalhe da ilustração da Fig. 2a que ressalta o pé da rainha e a extremidade de sua sandália. (Leblanc e Siliotti 1997: 123).

(2) Com exceção do disco solar, todos os elementos estão pintados de ocre, fazendo uma alusão ao ouro - material que compunha a coroa.

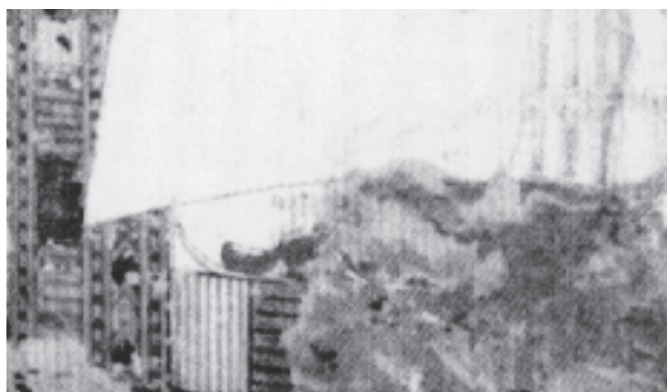




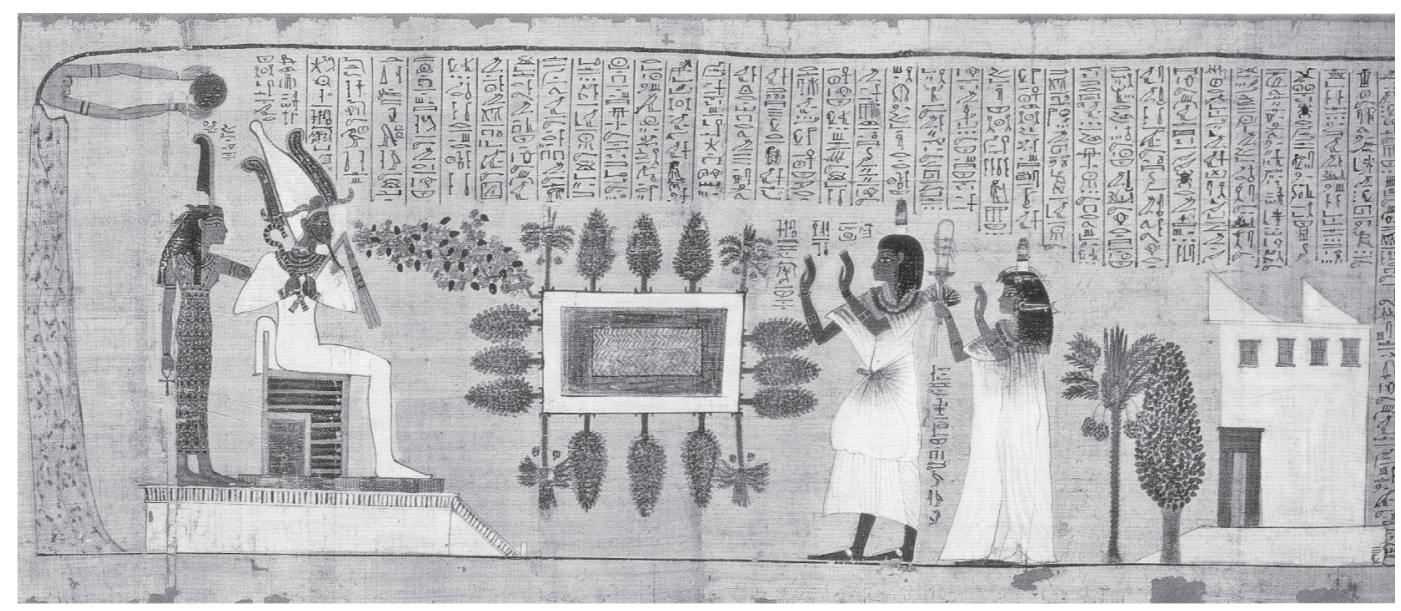

Fig. 3. Papiro de Livro dos Mortos de Nakht, final da 18 - início da 19a dinastia, Museu Britânico. (Russmann 2001: 196-197).

pelas pernas do deus. Ao pescoço, Osíris tem dois colares sobrepostos, o shebiu sobre o usekh. Com sua longa barba recurva e tez verde, já evidente em suas mãos expostas, o deus, com uma coroa atef multicolorida, olha a rainha de dentro de seu pavilhão ornado por serpentes uraeus, tendo à sua frente os quatro filhos de Hórus, igualmente mumiformes e em pé sobre um pequeno estandarte. $O$ registro continua na parede ao lado, com a presença de Anúbis logo atrás de Osíris.

O conteúdo simbólico desse registro pode não significar um encontro de Nefertari com o deus dos mortos no final de sua jornada, o que explicaria a razão de a cena estar na entrada de seu túmulo, mas um primeiro encontro logo quando do momento de sua morte ou pouco após isso. Uma representação semelhante pode ser apreciada no Livro dos Mortos de Nakht, datado do final da 18a início da 19a dinastia e pertencente à coleção do Museu Britânico (Russmann 2001: 196 197). Na imagem, Osíris não está no final da jornada, mas entre a antiga morada de Nakht e as montanhas do Ocidente, o novo lar do falecido. Um detalhe interessante na cena é que Nakht é o único personagem calçado nela, mas por tratar-se de uma representação privada, pode respeitar uma lógica própria ao discurso iconográfico destinado a essa categoria da elite (Fig. 3).
A segunda parede, à direita, é dividida em três partes. A porção inferior está decorada com ilustrações da coluna djed e do nó tyet. A parte mediana, tal como nas paredes oeste e norte da antecâmara, foi destinada à inscrição do capítulo 17 do Livro dos Mortos. Já o último terço, o registro superior que aqui será destacado, contém as vinhetas multicoloridas que acompanham os textos que se estendem às paredes mencionadas. A cena junto à entrada da antecâmara (Hawass 2006: 260, 261) nos revela Nefertari sentada sobre uma cadeira de encosto alto com pernas de leão, tendo entre estas uma decoração particular, o serekh. ${ }^{3} \mathrm{O}$ móvel, assim como o suporte do tabuleiro de senet que a rainha está jogando, estão sobre uma esteira de juncos. Nefertari, calçada com sandálias brancas, apresenta-se vestida com um ar de grande feminilidade por meio de um longo e transparente vestido aberto à frente, sem a fita vermelha mencionada na pintura anterior. Ela porta um bracelete no pulso esquerdo, um colar usekh e um brinco expressivo. O braço esquerdo estendese até o tabuleiro em uma cena congelada da movimentação das peças do jogo. O direito, mais abaixo e paralelo às pernas tem em sua

(3) Motivo decorativo que tem suas origens nas fachadas de palácios dos reis pré-dinasticos e do período Arcaico. 


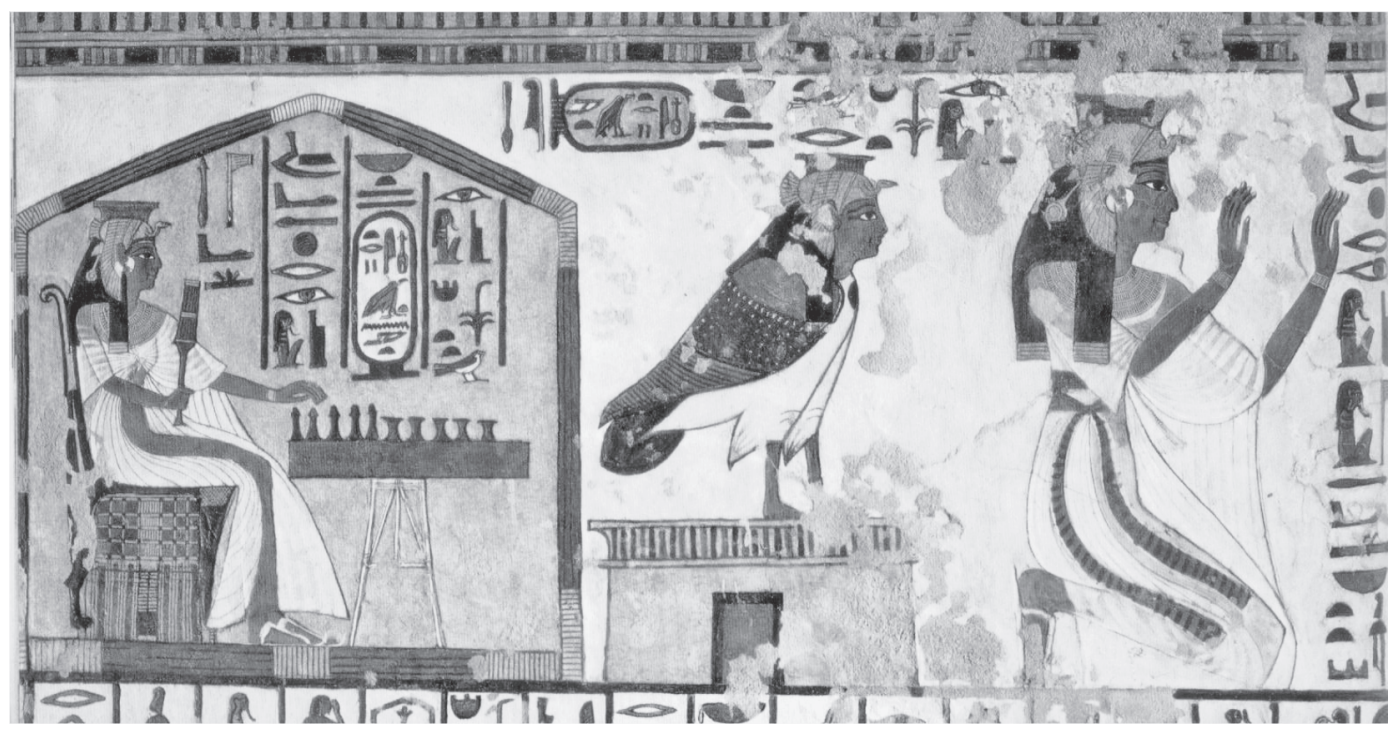

Fig. 4. Nefertari em três registros: jogando o senet, representada como pássaro Ba, e ajoelhada em adoração à representação de Aker (não presente na foto).Vestíbulo, parede sul à direita do corredor de entrada. (McDonald 1996: 58).

mão um cetro sekhem. À cabeça, Nefertari usa uma peruca tripartite decorada por um abutre e um modius. À frente dela, o texto diz: Osíris, a Grande esposa do rei, a Senhora das Duas Terras, Nefertari Mery-em-Mut, justificada por Osiris, o grande deus. O registro é emoldurado pela representação do quiosque de juncos que abriga a falecida. À direita, e voltada para a direita, encontramos a transfiguração da rainha sob a forma de seu $b a,{ }^{4}$ pousado sobre uma capela que faz alusão a seu próprio túmulo. Em seguida, e voltada para a mesma direção que as imagens anteriores, vemos a morta ajoelhada em atitude de adoração ao símbolo de Aker, ${ }^{5}$ ilustrado na parede transversal (Fig. 4).

O motivo pelo qual os registros dessas duas paredes terem aqui sido contemplados com uma atenção especial deve-se ao fato de serem os únicos, em toda a tumba, em que Nefertari é apresentada calçada. A princípio, é uma característica que pode passar despercebida, ainda mais porque por serem representadas brancas, as sandálias confundem-se facilmente com a cor de fundo das cenas, que é sempre branca - com exceção daquela da rainha jogando o senet. Para que possamos compreender o porquê da escolha desses locais para a figuração da rainha calçada e daí entender seu simbolismo, faz-se necessária uma comparação com outras fontes que tenham o mesmo contexto funerário. Assim, tomaremos como paralelo uma cena contida na câmara funerária do túmulo de Tutanhkamun (Reeves 1995: 72-74), 18a dinastia (c. 1336- 1327 a.C.) (Fig. 5) .

Da mesma forma que no caso de Nefertari, a imagem que tomaremos como parâmetro
(4) $\mathrm{O} b a$, normalmente associado à nossa noção para "alma”, é na verdade um conceito de difícil apreensão porque, ao contrário desta, o ba podia ter um modo de existência separado de seu dono, tal como é ilustrado pelo Diálogo de um homem com seu ba, um texto do Reinado Médio que traz em seu âmago a crise social do Primeiro Período Intermediário. No Livro dos Mortos, o ba simboliza a mobilidade e natureza humanas e é representado por um pássaro com cabeça humana (Allen 2002: 27-28).

(5) Divindade ctônia que está relacionada à união dos horizontes ocidental e oriental e, assim, à própria jornada do Sol no mundo subterrâneo. O símbolo é composto de dois leões virados para direções opostas, sustentando sobre seu dorso o símbolo para o horizonte (Shaw e Nicholson 1995: 19-20; Wilkinson 1996: 134-135; Lurker 1980: 24-25). 


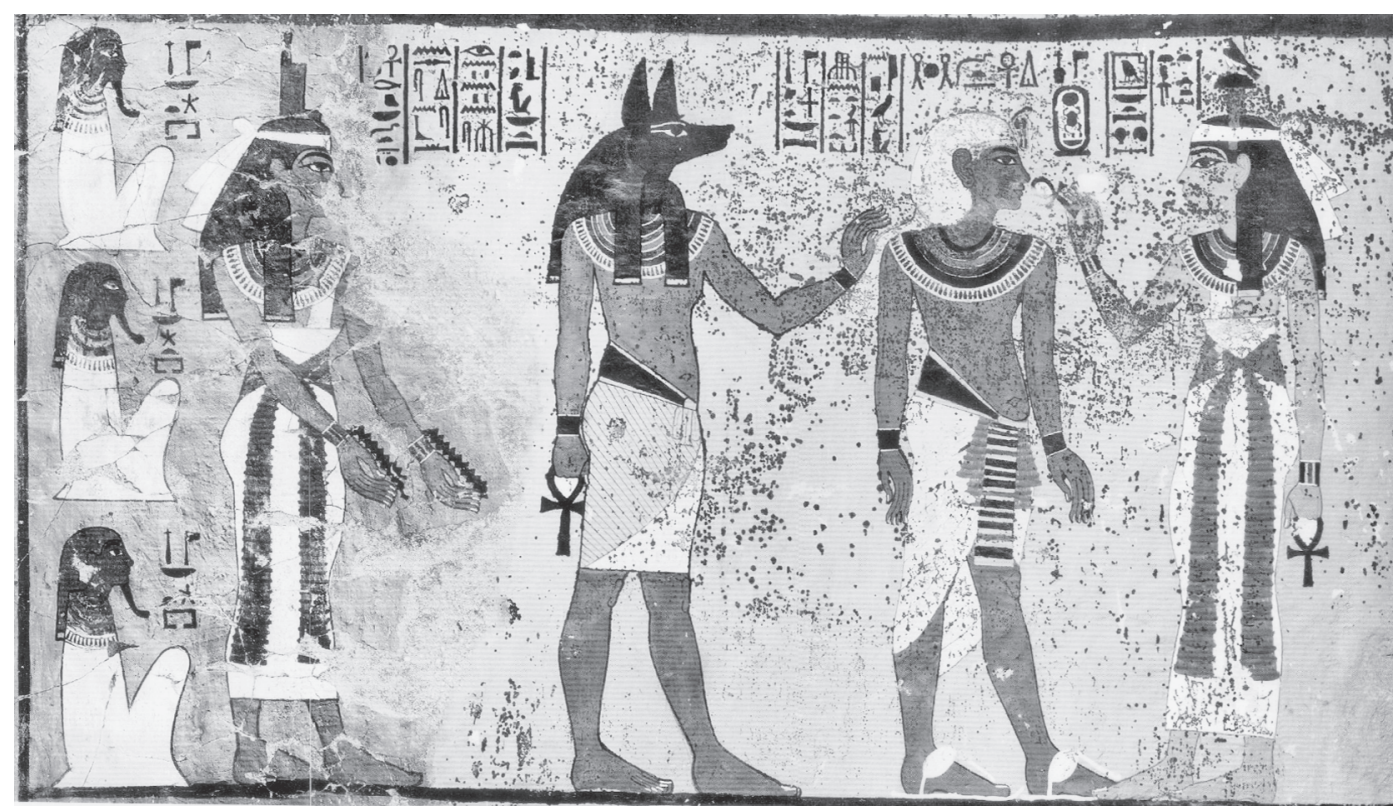

Fig. 5. Cena da parede sul do túmulo de Tutankhamun, 18a dinastia. (Wiese e Brodbeck 2004:78).

encontra-se na parede sul ${ }^{6}$ e ao lado de uma passagem, no caso a que dá acesso à antecâmara. A cena em questão mostra o rei ao centro, sendo guiado por Anúbis à esquerda, e sendo acolhido por Hathor como deusa do Ocidente à direita. $\mathrm{O}$ deus chacal estende o braço esquerdo sobre o ombro de Tutankhamun enquanto a deusa oferece o sopro da vida, representado pelo símbolo ankh, com sua mão direita próximo à narina do rei. Ambos os deuses seguram esse símbolo nas mãos que acompanham o contorno de seus corpos. Anúbis veste um saiote bicolor plissado com um cinturão atado por um nó tyet à frente e ostenta uma pesada peruca tripartite que, tal como o colar usekh que leva ao pescoço, emoldura sua face canídea. Os pulsos estão ornados por braceletes e seu pé traseiro (direito) apresenta dedos que, como as proporções das silhuetas dos personagens, revelam a herança estilística do período de Amarna. Na

(6) Na verdade, devido às condições da montanha em que foi escavado, o túmulo de Nefertari não se alinha perfeitamente com os pontos cardeais. Contudo, é de se acreditar que tal fato não era demasiado comprometedor e certos desvios eram aceitáveis. continuação esquerda do muro, em grande parte destruída pela passagem à antecâmara, está a deusa Ísis, vestida como Hathor e voltada para a direita, emoldurando, assim, Anúbis e Tutanhkamun. Em cada uma de suas mãos, a deusa tem um hieróglifo de um filete de água levado à altura de seu colo. No alto de sua cabeça, o hieróglifo do trono distintivo de sua identidade divina e, atrás dela, três divindades do mundo dos mortos.

Um aspecto interessante nessa composição é que, em todo o túmulo somente o faraó Ay, que aparece na parede norte, e um dos personagens ilustrados na procissão funerária na parede leste, apresentam os pés tratados de maneira naturalista, como a imagem de Anúbis: o exterior apresentando todos os dedos e o interior mostrando somente o perfil do pé com o hálux (Reeves 1995: 72-73; Wiese e Brodbeck 2004: 76-78). No contexto dos personagens da procissão funerária, talvez pela sobreposição destes tenha-se optado em dar mais detalhes ao pé do último. Se assim o foi, podemos ter aqui uma diferenciação entre os vivos mortais e aqueles que já pertencem a uma outra esfera, os defuntos e deuses. Anúbis seria não o deus propriamente dito, mas um sacerdote trajado como a divindade. 
Háthor veste um longo vestido branco e colante suspenso por uma alça presa ao ombro direito. À cintura, tem uma faixa com um nó cujas extremidades quase alcançam a parte inferior de seu vestido. Como Anúbis, usa um pesado colar usekh, braceletes e uma peruca tripartite - embora só um conjunto de cachos à frente esteja representado - presa por uma fita branca que também segura o símbolo imenty, que simboliza o Ocidente. Tutankhamun, por seu lado, aparece calçado com suas sandálias brancas que, ao contrário das pinturas de Nefertari, estão bastante realçadas pela cor de fundo que predomina na câmara funerária, o ocre, e com a própria cor de pele marromavermelhada do monarca. Sua cintura e parte das pernas estão cobertas por um saiote branco plissado, atado ao quadril por um cinturão com adereços frontais. Em torno do pescoço, porta um volumoso colar usekh, braceletes nos pulsos e um toucado afnet branco com uma serpente uraeus sobre a fronte. Seus braços acompanham a verticalidade de seu corpo, passivamente à ação da deusa que o acolhe em sua jornada ao além. Esta cena difere radicalmente daquelas do muro norte, onde Tutankhamun está completamente descalço como as próprias divindades. Somente Ay, o faraó que o sucedeu ao trono, aparece calçado porque é o único personagem do mundo dos vivos. O jovem rei, pela própria circunstância de aparecer desmembrado de seu ka e abraçando Osíris já é tido por um deus que habita uma esfera de existência distinta dos mortais.

O calçado apresenta-se como um divisor de mundos; ele delimita as fronteiras de significado entre o que é puro e o que não é, o que é sagrado e o que não é. E no caso específico das cenas descritas, ele também parece apontar para um momento de transição em que o indíviduo (Nefertari/Tutankhamun) embarca primeiramente calçado e, a partir de um certo momento, torna-se proibitivo apresentá-lo dessa forma. Por ser extremamente pequena e por ter sido elaborada às pressas, as pinturas do túmulo do jovem rei concentramse somente na câmara funerária, ao passo que no caso de Nefertari, todo o seu túmulo é decorado. Ainda assim, outros paralelos podem ser feitos com sepulturas reais da $19^{a}$ dinastia. Por serem bem mais extensas e por conterem diversos livros funerários decorados em suas paredes, as tumbas raméssidas apresentam em suas primeiras câmaras imagens do rei calçado. No caso do túmulo de Seti I (c.1294- 1279 a.C.), as últimas imagens em que o rei é ilustrado dessa maneira estão nos umbrais da porta que dá acesso ao corredor G. Os relevos, removidos por Champollion no séc. XIX, encontram-se atualmente nas coleções do Museo Egizio de Florença e no Museu do Louvre (Andreu et al. 1997: 137140) e retratam Seti I sendo recebido por Háthor em uma cena que encontra paralelo com aquela de Tutankhamun. Dali por diante, seguem registros do Ritual de Abertura da Boca, da Litania do Olho de Hórus, do Livro das Horas do Amduat e das Portas (Figs. 6a e 6b).

Nas imagens que acompanham esses textos onde a figura do rei é reproduzida, nenhuma apresenta o monarca calçado. Tal omissão não é de todo surpreendente, pois à medida que nos aproximamos da câmara funerária mais próximo estaremos da conclusão do drama da ressurreição do rei rumo à morada cósmica dos deuses, expressa pelas cenas da sala e por sua abóbada celeste, que outrora abrigava os seus ataúdes.?

Por outro lado, a título de contraste com as cenas de caráter funerário, podemos tomar como exemplo uma série de imagens em que Nefertari é representada calçada e cujo objetivo é afirmar suas ações e existência entre os vivos. Tal repertório iconográfico pode ser observado no templo que seu marido, Ramesses II, ergueu para ela em Abu Simbel, na Núbia, mais especificamente na montanha de Ibshek (Curto 1965: 318-332;

(7) Desta forma, no que concerne ao abandono da representação do rei calçado, há uma progressão rumo ao ponto mais sagrado do monumento, onde a figura real integra-se ao plano divino. É possível que nos templos a mesma linguagem tenha sido adotada à medida que nos aproximamos do santo dos santos. Contudo, muitos templos podem não apresentar uma coerência quanto a esse tipo de representação devido às várias alterações estruturais promovidas por diversos reis. 

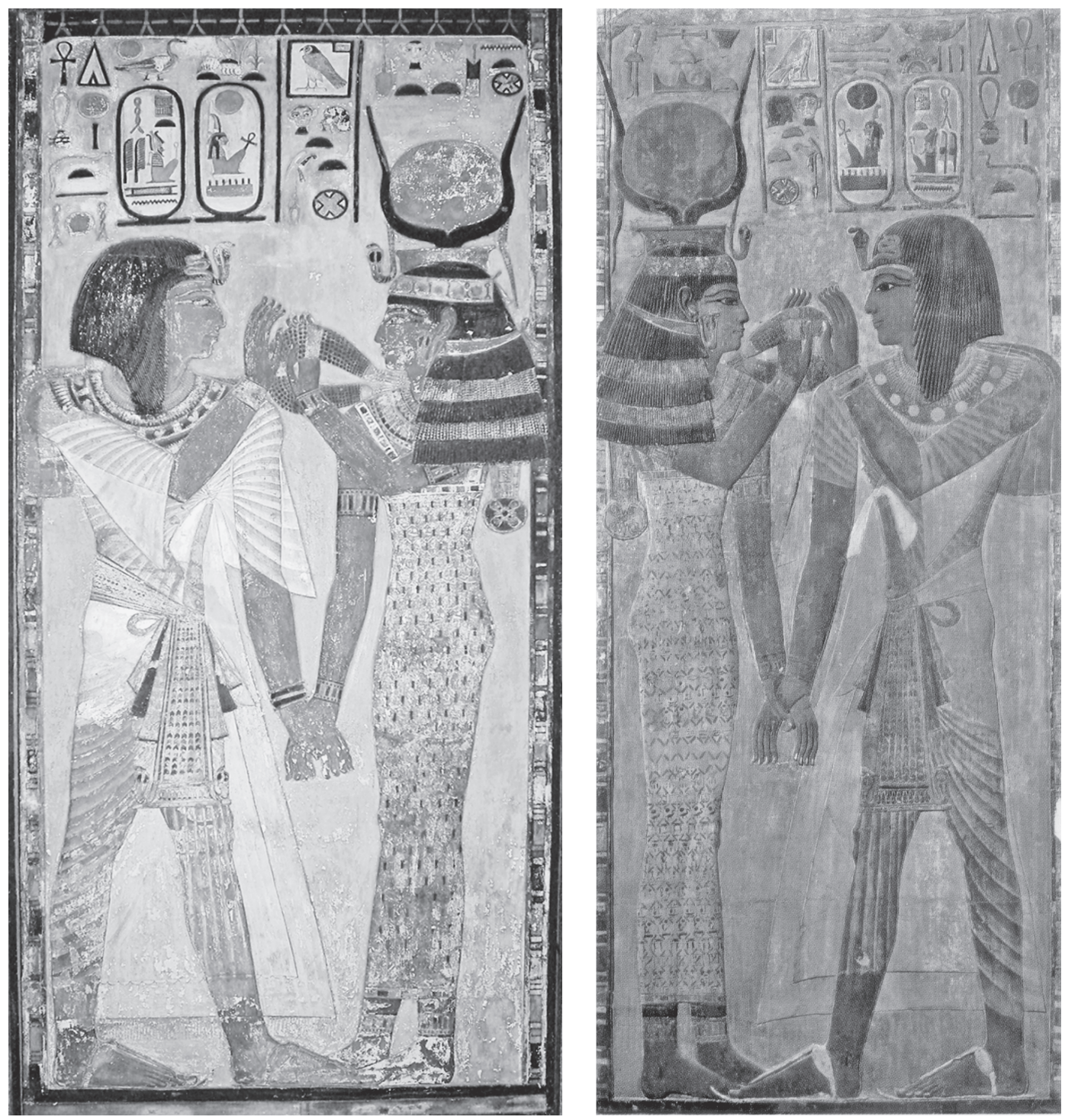

Figs. 6a e 6b. Umbrais provenientes do túmulo de Seti I, 19a dinastia. O da esquerda encontra-se na coleção do Museo Egizio de Firenze, enquanto o da direita está em exposição no Museu do Louvre. (Andreu et al. 1997: 137-140).

Desroches Noblecourt 1999: 231-244; PetersDestéract 2003: 280-324). ${ }^{8}$ O local, já consagrado à deusa Háthor, foi remodelado e a face rochosa da montanha deu lugar a seis

(8) Segundo alguns indícios, o templo foi escavado durante os primeiros anos de reinado de Ramesses II e antes daquele que seria construído na montanha de Meha, mais conhecido, e que apresenta quatro colossos do rei sentado na fachada (Desroches Noblecourt 1999: 231-244; PetersDestéract 2003: 281-324). colossos acompanhados, cada um, por duas figuras em menores proporções de cada lado. No interior do speos, ${ }^{9}$ em todas as paredes em que Nefertari é representada nos recintos do templo, ${ }^{10}$ ela aparece calçada, exceto em um

(9) Speos é uma cavidade escavada na rocha transformada em um templo (Goyon et al. 2004:157-161).

(10) O templo é constituído de uma sala hipóstila com seis colunas, de um vestíbulo e, no fundo e seguindo o eixo do corredor de entrada, do santuário. 
lintel ${ }^{11}$ sobre a porta que dá acesso ao santuário e quando aparece claramente divinizada ao lado de seu marido. ${ }^{12} \mathrm{O}$ teor dessas imagens reforça a importância do vínculo entre a representação do indivíduo calçado e sua existência terrestre. Ilustrá-lo dessa maneira significa afirmar que as ações ritualísticas registradas nas paredes do templo decorreram durante sua vida.

Ainda que alguns exemplos de reis calçados sejam conhecidos durante o reinado de Thutmes IV (Kozloff e Bryan 1992: 36-37) e Amenhotep III, foi a influência do período de Amarna que cristalizou a representação de personagens calçados na iconografia egípcia. Mais que um mero acessório que agregava status ao vestuário, as sandálias afirmavam, na perspectiva do programa iconográfico desse período, as circunstâncias do mundo dos vivos, tal como podemos apreciar nos registros dos talatats ${ }^{13}$ e das sepulturas de Tell-el-Amarna. Assim, a imagem do rei que tradicionalmente se via descalça passou a ser representada, em diversas ocasiões, calçada. Os motivos que cercam a ilustração das sandálias podem ser vários, dependendo do conteúdo da cena, e sua ausência não significa que o indivíduo não partilhe mais desta existência, tal como vemos em várias cenas de templos do Reinado Novo. Neste caso, podemos estar presenciando o testemunho de um ritual que o rei celebra diante de um local sagrado onde, tal como na célebre passagem bíblica do Êxodo $(3,5)$, o rei tira seus calça-

(11) No caso do lintel, por ser uma gravura de pequenas dimensões gravada sobre a rocha irregular da montanha, é possivel que os gravadores tivessem optado por não representar o casal com muitos detalhes assim como todo o restante. Todos os elementos representados registram quase que somente seus contornos (Peters-Desteract 2003: 315 . 316).

(12) Neste caso, é freqüente ver imagens de Ramesses II, calçado, adorando a si próprio como deus e descalço. (13) Talatats são pequenos blocos de pedra calcária ou arenito, cujas dimensões correspondem a 0,5 x 0,5 x 1 cúbito (aproximadamente $27 \times 27 \times 54 \mathrm{~cm}$ ). Por suas medidas e peso reduzidos em relação aos monumentais blocos tradicionalmente utilizados, permitiam a execução das construções em menor tempo. (Arnold 2003: 238; Goyon et al. 2004: 404). dos para não trazer impureza do mundo exterior para um espaço sagrado. As sandálias, por estarem vinculadas ao espaço exterior, transformam-se em tabu no espaço delimitado à epifania do deus na porção mais interior do santuário. Os calçados aqui em questão representam essa fronteira simbólica: se por um lado protegem o indivíduo da impureza do mundo, ${ }^{14}$ assim estabelecendo também uma distinção social, por outro, eles carregam consigo a própria essência deste mundo, uma vez que num universo puro e sacralizado - como aquele onde habitam as divindades - não há necessidade deles. ${ }^{15} \mathrm{Ao}$ contrário da cauda de touro, elemento do vestuário da realeza que passa a ser representado no saiote de divindades masculinas a partir do Reinado Antigo (De Araújo Duarte 2003), as sandálias ou outros calçados só passam a fazer parte da figuração dos deuses durante o período Romano. ${ }^{16}$ Mas enquanto a cauda representa a metáfora de uma potência sobrenatural compartilhada tanto por divindades quanto pelos reis, as sandálias estão diretamente relacionadas à sua função de proteção das impurezas presentes no chão deste mundo ou daquilo que se relaciona ao impuro, como os inimigos estrangeiros. E sua representação nas palmilhas desses calçados

(14) Um relevo no templo de Luxor apresenta o rei acompanhado pelos sacerdotes que carregam o andor com a barca sagrada na via de acesso no exterior do templo, tal como indicado pelos pilones da fachada atrás da procissão. Aqui, todos os personagens estão calçados (Wiese e Brodbeck 2004: 51).

(15) Algumas menções sobre divindades calçadas são feitas nos Textos das Pirâmides. Contudo, pela natureza abstrata das elocuções, não dá para se compreender com clareza se as passagens ocorrem na morada dos deuses. Na verdade, algumas partes do texto parecem evocar uma luta contra o caos circunscrita ao universo ctônio: W 203, 204; T15, 16, 141, 145, 248; P 466-67, 484, 551; N 309, 587; NT 256. (Allen 2005). De qualquer forma, no campo da iconografia, não há representações de divindades calçadas durante o período faraônico.

(16) Além da figuração dos calçados, há uma radical transformação na apresentação dos deuses, quando se lhes confere a imagem de oficiais, como a estátua de Hórus do British Museum (Luft 1998: 431), ou de membros da elite romana, como a imagem de Anúbis do Museo Gregoriano Egizio, no Vaticano (Rosati e Buranelli 1983: 31). 
tem duplo sentido: o de relacioná-los a tudo o que é impuro, e a sua submissão ao monarca egípcio, como atestam os exemplares descobertos no túmulo de Tutankhamun (Robins 1997: 158). Desta forma e na aritmética simbólica desta existência, o puro sobrepõe-se ao impuro, tal como a ordem deve subjugar o caos.

Por serem relacionadas às necessidades deste mundo, é compreensível que as sandálias também possam ser um indicador da fronteira entre esses dois mundos, o dos mortais vivos e o das divindades, vindo a servir de ponte entre a existência terrena para uma no além. À medida que um indivíduo deixava esta vida para passar para a próxima, sua essência transformava-se durante o processo e este não precisava mais ficar calçado quando habitasse na esfera das divindades porque passava a se identificar com elas.

\section{Conclusão}

Normalmente analisadas por seu aspecto pragmático como acessórios do vestuário ou por sua relação com os conceitos de purificação e domínio dos inimigos do Egito, as sandálias quando representadas em certos contextos podem ressaltar a passagem do indivíduo do mundo dos vivos para o dos mortos. Essas representações datam do final da $18^{\text {a }}$ dinastia e estendem-se, pelo menos, até o final do Reinado Novo. Entre os elementos que estão conectados à figuração do falecido nessa circunstância está o posicionamento da cena em locais que delimitam uma fronteira entre duas realidades de existência: o mundo dos vivos e o dos mortos. No caso do túmulo de Nefertari, os locais escolhidos estão na parede sul, à esquerda e direita do corredor de entrada. No de Tutankhamon, igualmente a parede sul e no túmulo de Seti I nos umbrais da porta que dá início ao corredor G. Estes são os últimos momentos em que o falecido é representado calçado e sua imagem está ou acompanhada de uma divindade que indica a transição para o Ocidente (Háthor) ou faz referência a seu governante (Osíris), ou sugere a passagem da pessoa para o além, como no caso das cenas da parede direita do túmulo de Nefertari, onde a rainha joga o senet sozinha e em seguida desmembra-se de seu $B a$. É possível que a mesma lógica seja aplicada às cenas de oficiais em suas sepulturas, espelhando o modelo adotado pela realeza e adaptando-o à temática iconográfica reservada a seus túmulos.

\section{Agradecimentos}

Gostaria de expressar meus sinceros agradecimentos ao Dr. Terence Duquesne, com o qual troquei diversas impressões a respeito deste tema e o qual teve a gentileza de me enviar uma série de documentos importantes. Também quero deixar registrada minha gratidão ao auxílio da Dra. Maria Isabel D’Agostino Fleming que teve a boa vontade de conferir e apoiar a publicação destes escritos. 
DE ARAÚJO DUARTE, C. Transition symbology on shod royal people representations in scenes from the second half of the New Kingdom. Revista do Museu de Arqueologia e Etnologia, São Paulo, 17: 293-304, 2007.

\begin{abstract}
Shod individuals depictions increase during the New Kingdom when for the first time royal people are illustrated in this way. Added to the basic meaning and function to protect from the soil and its impurities the sandals also contained illustrations of the classical enemies of Egypt in order that the Egyptian king, by means of magic, could submit them. However, in a series of paintings of that period which illustrate the shod monarchs in their tombs we can find the allusion to another meaning that when compared with other sources suggests the imminence of the transition to the other life.

Aiming to stress the mentioned aspect we will study the example of queen Nefertari tomb of the $19^{\text {th }}$ dynasty and some others in tombs situated in the Valley of the Kings.
\end{abstract}

Keywords: Ancient Egypt - Egyptian art - Sandals symbology - Funerary art.

\title{
Referências bibliográficas
}

ALLEN, J.P.

2002 Ba. In: Redford, D.B. (Ed.) The Ancient Gods Speak, a guide to Egyptian religion. Oxford, Oxford University Press: 27-28.

2005 The Ancient Egyptian Pyramid Texts. Atlanta: Society of Biblical Literature.

ANDREU, G.; RUTSCHOWSCAYA, M.-H.; ZIEGLER, C.

1997 L'Égypte Ancienne au Louvre. Paris: Hachette.

ARNOLD, D.

2003 The Encyclopedia of Ancient Egyptian Architecture. Cairo: The American University in Cairo Press.

CURTO, S.

1965 Nubia, storia di una civiltà favolosa. Novara: Istituto Geográfico De Agostini.

DE ARAÚJO DUARTE, C.

2003 Novas considerações quanto à datação do relevo de Wep-wawet proveniente de Lisht. São Paulo, Revista do Museu de Arqueologia e Etnologia, São Paulo, 13: 131-138.

DESROCHES NOBLECOURT, C.

1964 Tutankhamen, life and death of a pharaoh. London: The Connoisseur/Michael Joseph Ltd. Indicar referência no texto

1999 Le Secret des Temples de la Nubie. Paris: Stock/Pernoud.
GOYON, J.-C.; GOLVIN, J-C., SIMON-BOIDOT, C., MARTINET, G. 2004 La Construction Pharaonique. Paris: Picard. HAWASS, Z.

2006 The Royal Tombs of Egypt. London: Thames and Hudson.

KOZLOFF, A.P.; BRYAN, B.M.

1992 Egypt's Dazzling Sun, Amenhotep III and his world. Cleveland: Cleveland Museum of Art/Indiana University Press.

LEBLANC, C.; SILIOTTI, A.

1993 Nefertari e la Valle delle Regine. Firenze: Giunti.

LUFT, U.

1998 A Different World- Religious Conceptions. In: Schulz, R.; Seidel, M. (Orgs.) Egypt the World of the Pharaohs. Köln, Könemann: 416-431

LURKER, M.

1980 The Gods and Symbols of Ancient Egypt. Londres: Thames and Hudson.

MCDONALD, J. K.

1996 The Tomb of Nefertari, house of eternity. Cairo: The American University in Cairo Press.

PETERS-DESTÉRACT, M.

2003 Abou Simbel, à la Gloire de Ramsès. S.l.: Éditions du Rocher. 
REEVES, N.

1995 A la Découverte de Toutankhamon. Paris: Inter-Livres.

ROBINS, G.

1997 The Art of Ancient Egypt. Londres: British Museum Press.

ROSATI, G.; BURANELLI, F.

1983 Musei Vaticani: Egizi ed Etruschi. Florença: Scala.

RUSSMANN, E.R. (Org.)

2001 Eternal Egypt, masterworks of ancient art from the British Museum. Londres: British Museum Press.

SHAW, I.; NICHOLSON, P.

1995 The Dictionary of Ancient Egypt. Nova York: Harry N. Abrams.
VOGELSANG-EASTWOOD, G.M.

1999 Tutankhamun's Wardrobe: Garnments from the tomb of Tutankhamun. Rotterdam: Van waalwijk van doorn.

WEEKS, K.R.

2005 The Treasures of Luxor and the Valley of the Kings.Vercelli: White Star.

WIESE, A.; BRODBECK, A.

2004 Tutankhamun, the golden beyond. Tomb treasures from the Valley of the Kings. Basel: Antike Museum Basel \& Sammlung Ludwig.

WILKINSON, R.H.

1996 Reading Egyptian Art: a hieroglyphic guide to ancient Egyptian painting and sculpture. Londres: Thames and Hudson. 